\title{
Retinal Patching: A New Approach to the Manage- ment of Selected Retinal Breaks
}

\author{
C. E. GILBERT, I. GRIERSON and D. MCLEOD \\ London
}

\begin{abstract}
Summary
Restoration of retinal continuity by a patching technique is proposed as a new means of treating selected rhegmatogenous retinal detachments where established techniques frequently fail. The patch consists of a substrate and adhesive applied to the inner surface of the retina surrounding the retinal break. Bovine eye cup experiments have been performed to explore the effectiveness of a range of adhesives, and cyanoacrylates and Tisseel have been found to be effective. Studies of these adhesives on confluent cultures of bovine retinal pigment epithelial cells and glia revealed temporary cyanoacrylate toxicity and stimulation of proliferation by Tisseel. Substrate biocompatability was investigated by observing the growth of cells on various substrates in tissue culture; biological substrates such as lens capsule supported cell growth whereas synthetic membranes only did so if pretreated with fibronectin.
\end{abstract}

Attachment of the sensory retina to the underlying retinal pigment epithelium (RPE) is maintained by a combination of anatomical and physiological mechanisms. ${ }^{1}$ Retinal detachment occurs when these mechanisms are overwhelmed by traditional forces exerted from within the vitreous cavity, by the development of full-thickness retinal breaks, or by a combination of both. Surgical principles of management of retinal detachment include

(i) relief of vitreoretinal traction (using scleral buckling and/or vitrectomy techniques),

(ii) closure of retinal breaks (using scleral buckling and/or internal break tamponade with air, gas or silicone oil)

(iii) sealing retinal breaks (using cryothermy or laser photocoagulation to create a thermodestructive lesion which heals to form a chorioretinal scar)

Retinal reattachment occurs even if subretinal fluid is not drained during surgery by virtue of two physiological mechanisms; (a) passive diffusion along an osmotic gradient induced by high choroidal oncotic pressure,

(b) active evacuation of fluid from the subretinal space by a fluid pump in the RPE. 1

It is proposed that similar physiological mechanisms will reattach the sensory retina if retinal continuity is restored using a patch applied directly to retinal breaks after vitrectomy (Fig. 1). Closure of retinal breaks by patching will therefore obviate the need for break tamponade, break sealing and, to a certain extent, relief of traction and patching also offers several other theoretical advantages. After patching the retina will maintain its ability to slide over the RPE so avoiding the formation of secondary tears which are sometimes produced at the edge of chorioretinal adhesions if tangential vitreo retinal traction recurs postoperatively. Secondly, by restoring retinal continuity, patching will prevent the intravitreal migration of proliferating RPE cells which have been im- 
plicated in the pathogenesis of proliferative vitreoretinopathy (PVR). ${ }^{2}$

Management of retinal breaks by patching should also prevent the complications of break sealing. Cryothermy is associated with uveitis $^{3}$ and release of viable RPE cells into the vitreous cavity. ${ }^{4}$ Cryothermy also causes breakdown of the blood-retina barrier by mechanical disruption and by stimulating a local inflammatory reaction, which promotes accumulation of serum proteins (including
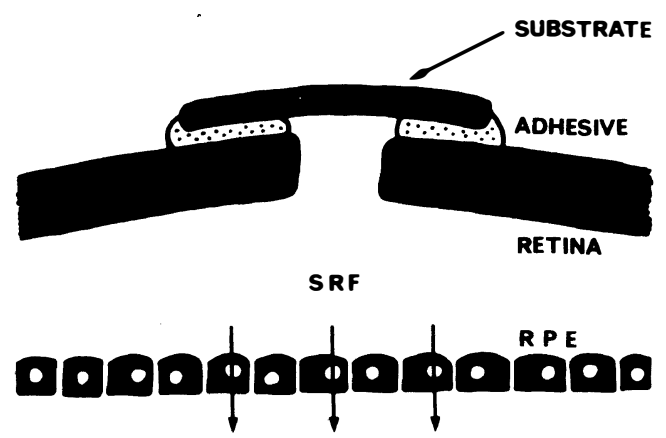

Fig. 1. Diagram to illustrate retinal reattachment after restoration of retinal continuity with a patch.

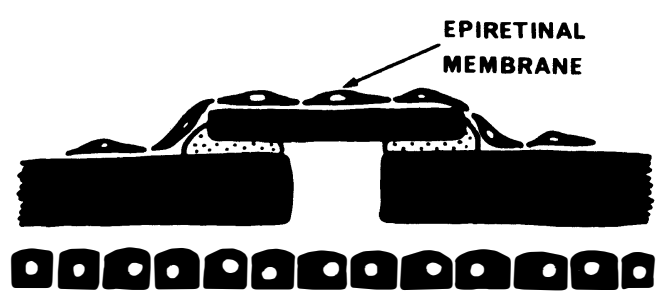

Fig. 2. Diagram to illustrate how a patch might act as a scaffold for cellular repair.

Table I Characteristics of an ideal adhesive and substrate for retinal patching

\begin{tabular}{ll}
\hline Ideal Adhesive & Ideal Substrate \\
\hline Good adhesion to retina & Non toxic \\
Good adhesion to substrate & Non inflammatory \\
Non toxic & Supports cell growth \\
Non inflammatory & Easy to prepare and \\
& store \\
Easy to deliver & Easy to deliver \\
Suitable setting time & Easy to manipulate \\
Sterilisable & Sterilisable \\
Malleable once set & Easy to visualise \\
Easy to visualise & \\
\hline
\end{tabular}

fibronectin and platelet-derived growth factor) in the vitreous cavity. ${ }^{5}$ These compounds have been shown to be chemoattractants for RPE cells ${ }^{6}$ and to stimulate proliferation of dermal fibroblasts in vitro. ${ }^{7}$ Patching retinal breaks will therefore not only promote retinal reattachment but may also reduce the incidence of PVR.

Retinal breaks do not heal naturally, probably because cells, such as glia, that could potentially take part in a repair process, need a scaffold on which to migrate and proliferate. It is proposed that a patch would provide such a scaffold and that, even if the patch was not permanent, the cellular response would maintain retinal continuity. Retinal Müller cells migrate through the internal limiting lamina in response to a number of stimuli ${ }^{8}$ and contribute significantly to the cellular component of epiretinal membranes. ${ }^{9}$ One problem envisaged is that this response may not remain limited to the region of the patch (Fig. 2).

Based on the theoretical concepts discussed above it is possible to conjecture ideal characteristics for adhesives and substrates which could be used to make up a retinal patch (Table I). The preliminary in vitro studies undertaken to examine some of these aspects are reported in this paper.

\section{Materials and Methods}

The purposes of our investigations fall into three categories:

(i) To examine the adhesive properties of several adhesives to bovine retina and to a variety substrates in vitro.

(ii) To study the effects of "successful" adhesives on retinal cells in tissue culture.

(iii) To investigate the biocompatability of substrates in tissue culture.

\section{(1) Patch adhesives:}

The adhesives investigated include both synthetic and naturally occurring substances. Synthetic adhesives tested were Polyacrylic Acid (Dentsply) and Poly-F (Dentsply), as used in Dentistry, and Silastic Adhesive (Dow Corning) and Medical Adhesive 355 (Dow Corning). A variety of cyanoacrylate adhesives were tested including Avacryl 
(CRX Medical). Histoacryl (B Braun Melsungen $A G)$ and other N-Butylcyanoacrylates (CRX Medical) of varying viscosities. Naturally occurring glues investigated were the cellular attachment factors fibronectin (Sigma). laminin (Collaborative Research). and Matrogel (Collaborative Research) which contains laminin. collagen type IV. heparan sulphate proteoglycan and entactin. Three preparations of fibrin were tested: the first was prepared by mixing chick plasma with chick embryo extract (Difco Labs.), another was reconstituted from freeze dried fibrin (Sigma) and the third was Tisseel. ( $1 \mathrm{~m}$ muno Ltd.), which contains fibrinogen. Factor XIII, thrombin. calcium chloride and aprotonin (an anti-fibrinolytic agent) and which forms cross linked fibrin.

\section{(2) Patch substrates:}

The substrates investigated include synthetic and naturally occurring membranes. High viscosity silicone oil (6).(1)(0) c/s) was spread on a glass slide and gently heated until the superficial layers had polymerised, forming a thin membrane." Polyethylene (Steridrape. 3M) was also used. Bovine Descemets membrane wals prepared according to Kenney"l and bovine anterior lens capsule used after removing anterior epithelial cells with EDTA and trypsin. Thin lamallac of bovine sclera and bovine cornea were prepared by $t$ hours exposure to ultraviolet light to kill the fibroblast and keratocyte cell population.

\section{(3) Ele cup ciperiments:}

Eye cups were prepared from freshly enucleated bovine eyes by removing the anterior segments and vitreous after making a $36(1)^{\circ}$ pre-equatorial incision. A small retinotomy (approximatcly $2 \mathrm{~mm}$ by $2 \mathrm{~mm}$ ) wats created using fine forceps and spring scissors, taking care not to damage the RPE. The substrate to be tested was trimmed so that it was large enough to cover the retinotomy and a small rim of retina around the defect. The adhesive to be assessed was drawn up in a tuberculin syringe and delivered via a 21 gauge needle. The substrate was placed so as to completely cover the retinutomy and the adhesive applied in minute drops to the edge of the substrate so that a complete seal to the retina wals achieved (Fig 3a). Integrity of the patch was evaluated by raising a small localised retinal detachment under the patch by injecting balanced salt solution through a small peripheral retinotomy (Fig 3b). The adhesive quality of the adhesive was investigated by filling the eye cup containing the patch with minimal essential media (MEM) and placing the eve cup on a Luchman shaking platform set at Mark + for two hours. If the patch was still adherent to the retina after this period the adhesive was deemed a "success".

\section{(4) Tissue culture studies of adhesives:}

Effects of "successful" adhesives were examined on confluent cultures of bovine $\mathrm{RPE}$ and bovine glia in tissue culture. RPE cells were established in primary culture using a modification of the technique described by Ross. "' and glial cultures were obtained using a technique modified from

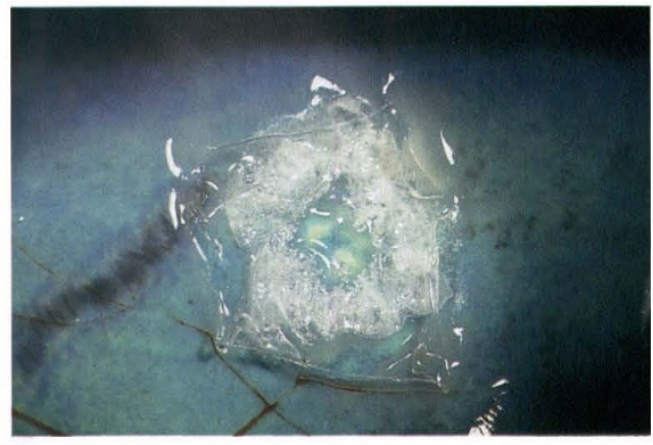

a

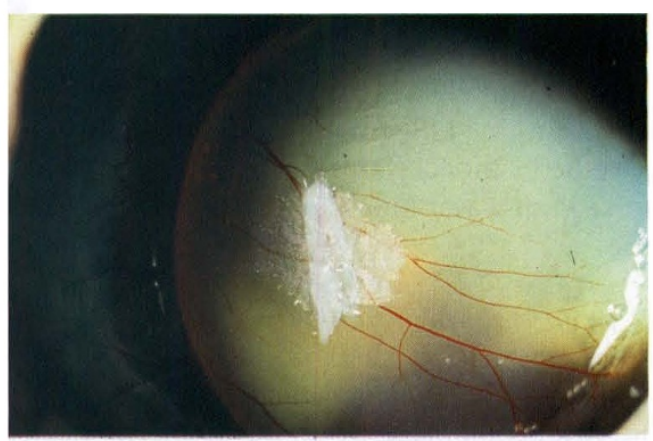

b

Figs. 3a and b. 3a. Re'linal palch made from bovine anterior capsule and Alocryl adlessive repairing a retinotom! created in bovine retina in an e've cup. 3b. Patch integrity assessed by creating alocalised re'tinal ele'vation. 
Burke. ${ }^{13}$ (For details of morphology and characterisation of bovine glia in culture see Savage et al. ${ }^{14}$ ) Confluent cultures of 5 th passage RPE and 8th passage glia were used in these experiments. Histoacryl was drawn up in very fine polythene tubing attached to a syringe and a micrometer (Dixon) and $3 \mathrm{uL}$ drops of adhesive allowed to set directly onto the cell monolayer after the media had been discarded. Fresh media was added and the cells incubated for two weeks under standard tissue culture conditions. $0.5 \mathrm{ml}$ of crosslinked fibrin was prepared by mixing the components of Tisseel and this was added to tissue culture flasks after changing the media. The flasks were examined and photographed daily using a phase contrast microscope (Nikon).

\section{(5) Biocompatability studies of substrates:}

Biocompatability of the substrates was investigated by attaching $8 \mathrm{~mm}$ by $8 \mathrm{~mm}$ samples of the substrate to the bottom of $25 \mathrm{~cm}$ tissue culture flasks using wax. Bovine retinal glia and RPE cells were passaged into the flasks in the usual manner and daily observations made using phase contrast microscopy. In a further experiment $1 \mathrm{uL}$ of $0.1 \%$ fibronectin (Sigma) was coated onto the synthetic substrates prior to passage of the cells in order to promote cell attachment.

\section{Results}

\section{(1) Retinal adherence studies:}

The only adhesives that successfully adhered to bovine retina in vitro were the cyanoacrylates and Tisseel. Attempts were made to apply the patch with the eye cup filled with MEM but this failed with both types of adhesive; the cyanoacrylates because they are less dense than water and Tisseel because it is soluble.

(2) In vitro studies of adhesives:

Tissue culture toxicity studies were performed using Histoacryl and Avacryl. Morphological changes were observed in both RPE and glial cells in the immediate vicinity of polymerised cyanoacrylates within a few hours of application. The cells retracted, became rounded and separated from the flask. At three days these changes were maximum, with a cell-free halo measuring up to $2.5 \mathrm{~mm}$ surrounding the drop of polymerised adhesive (average diameter of glue $6 \mathrm{~mm}$ ) (Fig. 4a). After one week repopulation of this denuded area had started via migration and proliferation of peripheral undamaged cells, and by two weeks the cells had grown back to the edge of the adhesive (Fig. 4b). Preliminary studies with Tisseel suggest that this fibrin preparation stimulates the proliferation of bovine retinal glial cells.

\section{(3) Biocompatability studies of substrates:}

None of the synthetic substrates supported the growth of cells without pretreatment with fibronectin. Under these circumstances a vigorous population of cells grew initially on the fibronectin treated area, but after a few days the colony of cells retracted, rolled up and finally lost its attachment to the substrate (Fig. 5a). On the other hand, biological substrates such as bovine anterior capsule supported a vigorous growth of cells (Fig. 5b,c).

\section{Discussion}

Despite the wide range of treatment options certain retinal breaks remain difficult to close and seal. Internal break tamponade with silicone oil or gas demands prolonged uncomfortable posturing, especially for inferior breaks, and retinal breaks overlying colobomata pose an especially difficult but rare problem as the absence of RPE and choroid in the colobomatous area precludes conventional sealing u'sing thermodestructive techniques. ${ }^{15}$ Furthermore, whilst certain macular breaks respond to gas tamponade with or without vitrectomy, ${ }^{16}$ others require laser photocoagulation in the region of the break, so increasing the size of the eventual central scotoma. Finally, in combined rhegmatogenous and traction retinal detachments, relief of all vitreoretinal traction by vitrectomy and membrane dissection is not always possible without extensive retinotomy or retinectomy. ${ }^{17}$ Using the surface tension effects of a silicone oil bubble it is sometimes possible to close certain retinal breaks and to limit the extent of detachment by eliminating the rhegmatogenous component. Retinal patching may be another means of producing such "rhegmatogenous confinement" in these 
difficult cases, thus avoiding the complications of silicone oil ${ }^{18-26}$ or potential stimulation of PVR by retinotomy or retinal thermodestruction.

Retinal glueing has been explored experimentally and clinically using a variety of adhesives and modes of application. ${ }^{27-37}$ The aim of glueing is to achieve a strong and immediate adhesion between the retina and RPE (Fig. 6a, b). Cyanoacrylate retinopexy has been successfully used in selected patients, the majority of whom either had inferior breaks or where extensive retinectomy was required to produce preoperative retinal flattening. ${ }^{33}$ In the glueing technique the adhesive is applied directly onto the
RPE, whereas in patching the materials are applied to the inner surface of the retina, leaving the RPE undisturbed. This will limit any toxic, inflammatory or stimulatory effects that the glue and substrate may have on the choroid and RPE. Plugging of retinal breaks as a variant of patching was employed by Peyman et al ${ }^{38}$ but only as an adjunct to break sealing and internal tamponade.

Only tentative conclusions can be drawn at this stage as to which adhesive and substrate may prove the most effective patching materials. The cyanoacrylates are powerful adhesives and have been shown to persist for long periods in the posterior segment, but they have several disadvantages. They polymerise
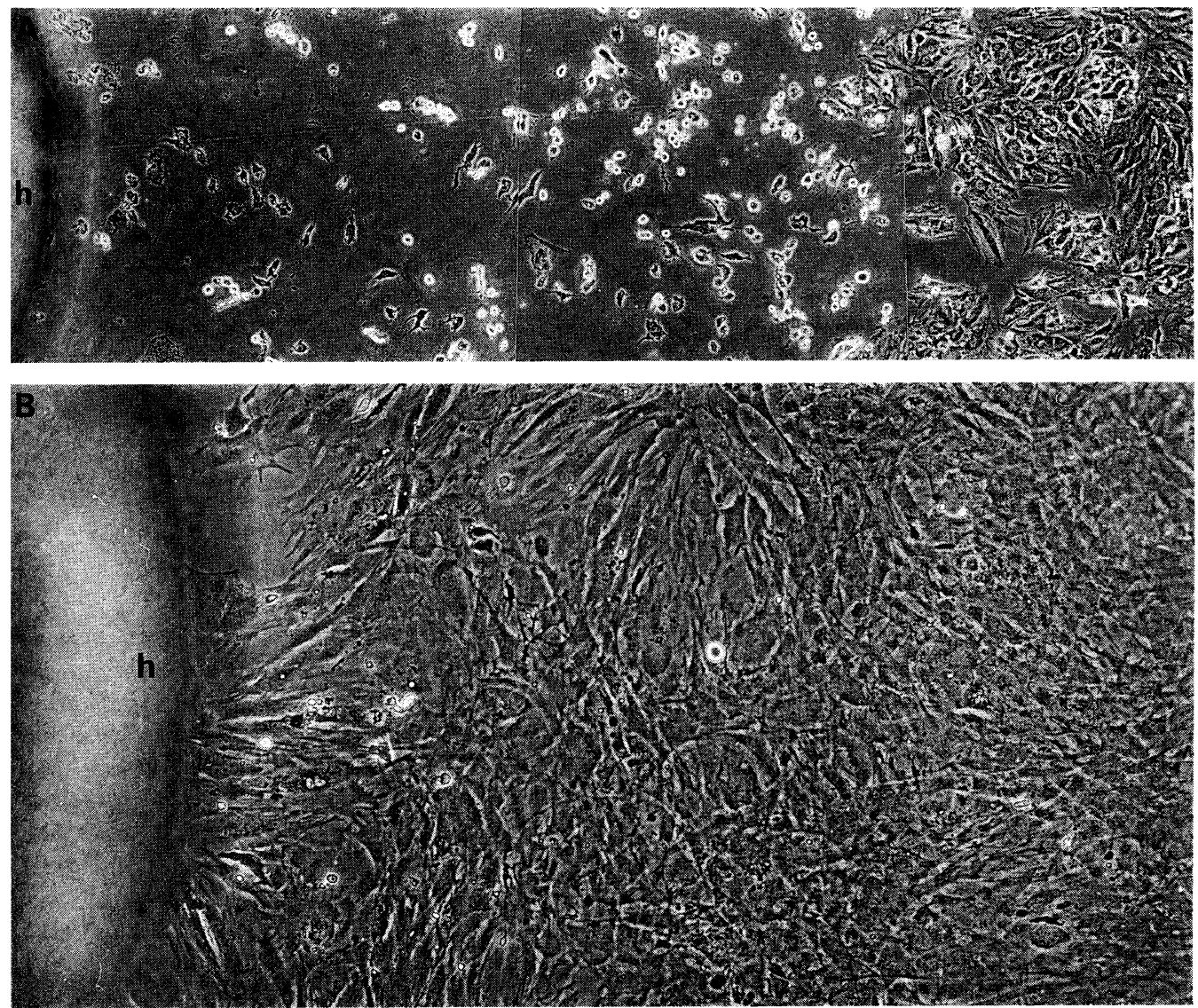

Fig. 4a. Retracted, dying bovine retinal glial cells adjacent to a $3 \mu l$ drop of polymerised Histoacryl adhesive; 24 hours after application of the adhesive onto a confluent monolayer of cells. (Magnification $\times 75$. $\boldsymbol{h}=$ Histoacryl.) Fig. 4b. Two weeks after application of Histoacryl glial cells have repopulated the denuded area by migration and proliferation of peripheral healthy cells. $($ Magnification $\times 150 . h=$ Histoacryl.) 
very rapidly, which makes application and delivery difficult, although this can be modified by adding Iophendylate (Lafeyette).
Cyanoacrylates cannot be applied in an aqueous environment as they are less dense than water; this means that they would have to be
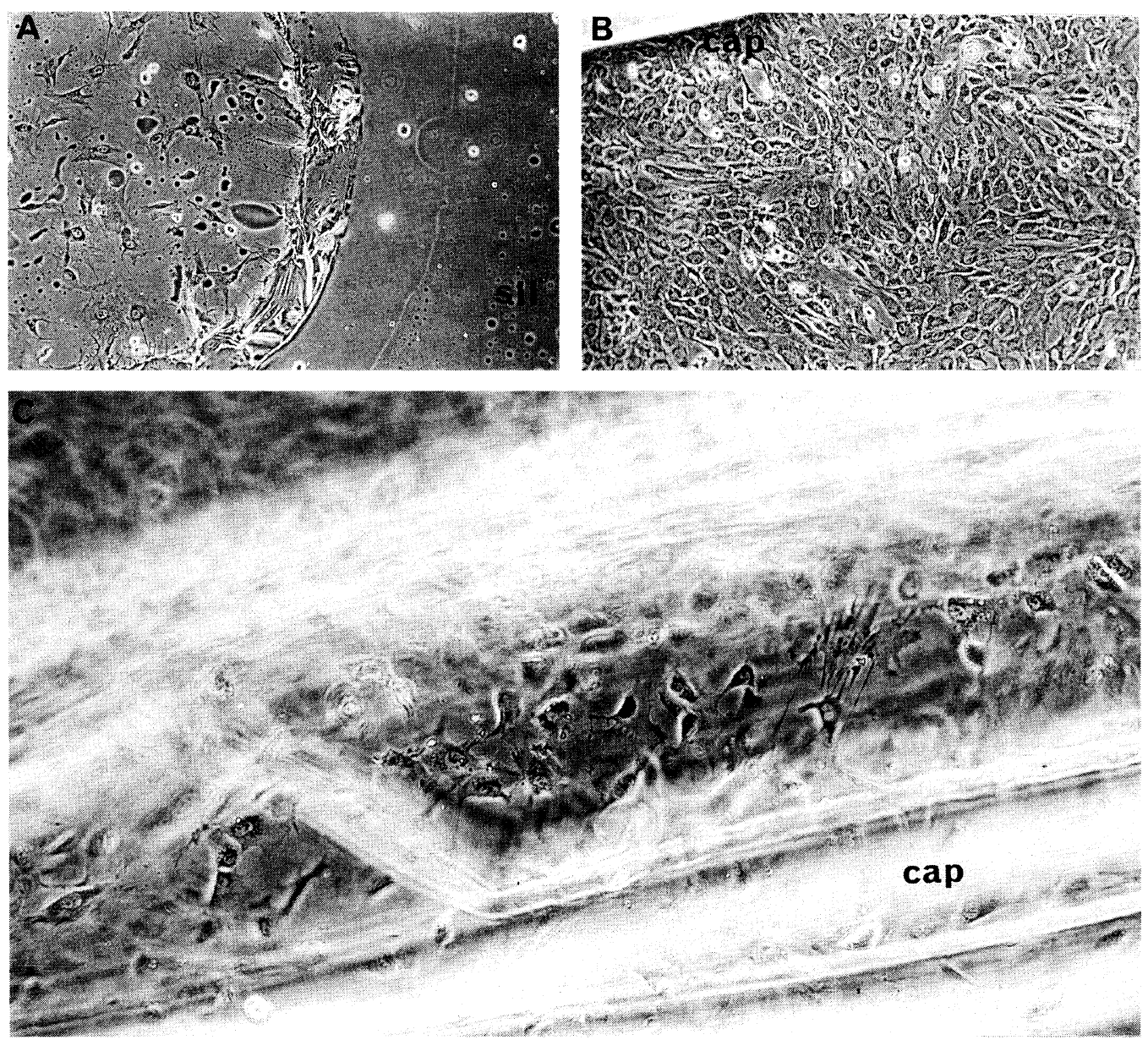

Fig. 5a. Bovine glial cells growing on portion of silicone membrane pretreated with fibronectin showing early loss of attachment to substrate. $($ Magnification $\times 75$. sil $=$ silicone). Fig. 5 b. Vigorous population of glial cells growing on bovine anterior lens capsule. (Magnification $\times 75$ ). Fig. 5b. Retinal glial cells growing on curled up anterior lens capsule 24 hours after passage of cells (Magnification $\times 150$ )

A

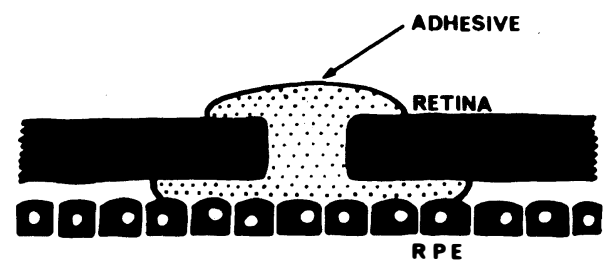

B

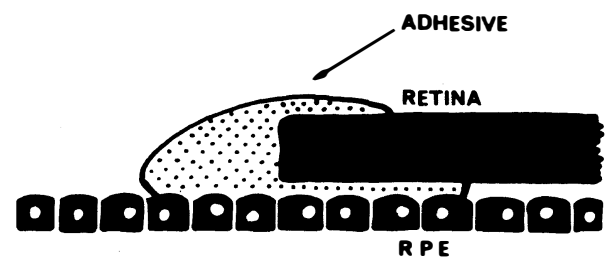

Fig. 6a. Diagram to illustrate retinal break sealing using a retinal glueing technique. Fig. $\mathbf{6 b}$. Diagram to show how glue retinoplexy can be used to secure the edge of a retinectomy. 
applied after a fluid/gas exchange, which may limit the circumstances in which they could be used. During polymerisation cyanoacrylates produce heat and release formaldehydes and alkyl-cyanoacetate, ${ }^{39}$ which are probably responsible for the retinal toxicity demonstrated in an animal model ${ }^{34} \mathrm{We}$ have demonstrated that cyanoacrylates are toxic to RPE and retinal glia in vitro, although the observed repopulation suggests that the toxic effects are short lived. More recently developed cyanoacrylates (such as octylcyanoacrylate), are less toxic ${ }^{40}$ and can be prepared in a form that has a longer polmerisation time; they may prove more useful than Histoacryl. Tisseel appears to be non-toxic to retinal glia in tissue culture; indeed proliferation is stimulated. However, doubts exist as to the adhesive qualities of fibrin in the posterior segment. ${ }^{36}$ Further studies are planned to investigate whether modulation of Tisseelinduced cell proliferation and delaying fibrinolysis (e.g. by varying the aprotonin content) will enable this adhesive to be used in retinal patching.

The synthetic substrates investigated, although easier to prepare, sterilise and handle than the naturally occurring membranes, do not support the growth of cells in vitro which may limit the permanence of a patch made with these materials. Pretreatment with fibronectin, by encouraging temporary cell growth, may aid incorporation of the patch into the retina so producing a permanent repair. Alternative synthetic: substrates, such as hydrogels, will be explored in the future; they may be more readily modulated in respect of cellular incorporation into the retina. In vivo experiments are planned to investigate the practical and technical difficulties associated with retinal patching, and to investigate the inflammatory and cellular reactions to the patching materials.

\section{Conclusions}

Better understanding of the pathogenesis of rhegmatogenous retinal detachment and advancement in surgical techniques have resulted in improved rates of retinal reattachment, even in cases that were previously considered inoperable. Retinal patching is proposed as an additional treatment modality that may have some part to play in the management of selected retinal detachments where established techniques currently fail.

This study was supported by T. F. C. Frost Charitable Trust and the Help the Hospitals Charity.

\section{References}

${ }^{1}$ Foulds WS: Aetiology of Retinal Detachment. Trans Ophthalmol Soc UK 1975, 95: 118-27.

2 Machemer $\mathrm{R}$ and Laqua $\mathrm{H}$ : Retinal Pigment Epithelial Proliferation in Retinal Detachment. Am J Ophthalmol 1975, 80: 1-23.

${ }^{3}$ Chignell AH, Clemett RS and Revi IHS: Pigment Fallout and Uveitis after Cryothermy. Br J Ophthalmol 1973, 57: 156-65.

${ }^{4}$ Campochiaro PA, Kaden IH, Viduarri-Leal J, et al: Cryothermy Enhances Intravitreal Dispersion of Viable retinal Pigment Epithelial Cells. Arch Ophthalmol 1985, 103434.

5 Campochiaro PA, Bryan JA, Conway BP, Jaccoma EH: 'Intravitreal Chemotactic and Mitogenic Activity. Implication of Blood Retinal Barrier Breakdown. Arch Ophthalmol 1986, 104 1685-7.

${ }^{6}$ Campochiaro PA, Jerdan, JA, Glaser BM: Serum contains Chemoattractants for Human Retinal Pigment Epithelium. Arch Ophthalmol 1984, 102: 1830-3.

${ }^{7}$ Burke JM: Cultured Retinal Glial Cells are Insensitive to Platelet-Derived Growth Factor. Exp Eye Res 1982, 35: 663-9.

${ }^{8}$ McLeod D, Hiscott PS, Grierson I: AgeRelated Cellular Proliferation at the Vitreoretinal Juncture. Eye 1987, 1: 263-81.

${ }^{9}$ Grierson I, Hiscott PS, Hitchins CA, McKechnie NM, White VA, McLeod D: Which Cells are Involved in the Formation of Epiretinal Membranes? Seminars in Ophthalmology 1987, 2: 99-109.

${ }^{10}$ Harris AK, Wild P, Stopak D: Silicone Rubber Substrate: A New Wrinkle in the Study of Cell Locomotion. Science 1980, 208: 177-9.

${ }^{11}$ Kenney MC, Benya PD, Nimni ME, Smith RE: A New Technique for Isolation of Descements Membrane: Preliminary Studies. Invest Ophthalmol Vis Sci 1979, 18: 527-32.

12 Ross E: Culture of Mammalian Retinal Pigment Epithelium and Neural Retina. Methods in Enzymology 1982, 81: 39-43.

${ }^{13}$ Burke JM, Foster SJ: Culture of Adult Rabbit Retinal Glial Cells: Methods and Cellular Origin of Explant Outgrowth. Curr Eye Res 1984, 3: $1169-78$.

${ }^{14}$ Savage F, Day J, Hogg P, Grierson I: Tissue Culture of Retinal Glia. Eye 1988, 2: Suppl 5164-79. 
${ }^{15}$ Cooling RJ, Feretis EB: Retinal Detachment and Chorio-Retinal Coloboma. S Afr Arch Ophthalmol 1983, 10: 9-18.

${ }^{16}$ Billington $\mathrm{BM}$ and Chignell $\mathrm{AH}$ : Treatment of Rhegmatogenous Retinal Detachment Uncomplicated by Massive Periretinal Proliferation by Pars Plana Vitrectomy. Trans Ophthalmol Soc UK 1985, 104: 120-2.

17 Jacobs PM, Cooling RJ, Leaver PK, McLeod D: Retinal Relieving Incisions. Eye 1987, 1: 500-3.

${ }^{18}$ Cockerham WD, Schepens CL, Freeman HM: Silicone Injection in Retinal Detachment. Arch Ophthalmol 1970, 83: 704-12.

${ }^{19}$ Kanski JJ and Daniel R: Intravitreal Silicone Oil in Retinal Detachment. $\mathrm{Br} J$ Ophthalmol 1973, 57 542-5.

${ }^{20}$ Leaver PK, Grey RHB, Garner A: Silicone Oil Injection in the Treatment of Massive Preretinal Retraction II Late Complications in 93 Eyes. Br J Ophthalmol 1979, 63: 361-7.

${ }^{21}$ Haut J, Ullern M, Chermet M, Van Efferterre G: Complications of Intraocular Injections of Silicone Combined with Vitrectomy. Ophthalmologica (Basel) 1980, 180: 29-35.

${ }^{22}$ McCuen BW, de Juan E; Landers MB, Machemer R: Silicone Oil in Vitreoretinal Surgery: 2 Results and Complications. Retina 1985, 5: 198-205.

${ }^{23}$ Laqua H, Lucke K, Forester M: Results of Silicone Oil Surgery. Jpn J Ophthalmol 1987, 31: 124-31.

${ }^{24}$ Yeo JH, Glaser BM, Michels RG: Silicone Oil in the Treatment of Complicated Retinal Detachments. Ophthalmology 1987, 94: 110913.

${ }^{25}$ Sebag J, Zucker CL, Pankratov MM, Refojo F, Melgen S, Schepens C: Silicone Oil Induced Changes in Squirrel Monkey Retinal Morphology. Invest Ophthalmol Vis Sci 1988, Suppl 29: 403.

${ }^{26}$ Rockland KS, Pankratov MM, Sebag J, Zucker CL, Refojo MF, Schepens C: Central Nervous System Changes Following Intraocular Injection of Silicone Oil in Squirrel Monkeys. Invest Ophthalmol Vis Sci 1988, Suppl 29: 405.

${ }^{27}$ Kurokawa K: Experimental Studies on the Retinopexy using Cyanoacrylate in the Rabbits Eye. Acta Soc Ophthalmol Jpn 1972, 76: 831-43.

${ }^{28}$ Spitznas M, Lossagk H, Vogel M, Joussen F:
Intraocular Histocompatibility and Adhesive Strength of Butyl-2-Cyanoacrylate. Albrecht V Greafes Arch Klin Exp Ophthalmol 1973, 187: $102-10$.

${ }^{29}$ Faulborn J: Treatment of Giant Retinal Tears after Perforating Injuries with Vitrectomy and Cyanoacrylate Tissue Adhesive. $A d v$ Ophthalmol 1976, 33: 304.

${ }^{30}$ McCuen BM II, Hida T, Sheta SM, Isbey EK, Hahn DK, Hickingbotham D: Experimental Transvitreal Cyanoacrylate Retinopexy. Am J Ophthalmol 1986, 102: 199-207.

${ }^{31}$ Sheta SM, Hida T, McCuen BW II: Experimental Transvitreal Cyanoacrylate Retinopexy Through Silicone Oil. Am J Ophthalmol 1986, 102: 717-22.

${ }^{32}$ Hida T, Sheta SM, Proia AD, McCuen BW II: Experimental Transvitreal Cyanoacrylate Retinopexy in a Primate Model. Am J Ophthalmol 1987, 103: 782-9.

${ }^{33}$ McCuen BW II, Hida T, Sheta SM: Transvitreal Cyanoacrylate Retinopexy in the Management of Complicated Retinal Detachment. Am J Ophthalmol 1987, 104 127-32.

${ }^{34}$ Hida T, Sheta SM, Proia AD, McCuen BW II: Retinal Toxicity of Cyanoacrylate Tissue in the Rabbit. Retina 1988, (In Press)

${ }^{35}$ Brown AL, Nantz FA: The Use of Fibrin Coagulum Fixation in Ocular Surgery. Trans Acad Ophthalmol Otolaryngol 1949, 54: 12630.

${ }^{36}$ Nasaduke I, Peyman GA: Intraocular Effects of Rabbit Fibrin Sealant used in Experimental Retinal Holes and Retinal Detachment. Ophthalmology-Neurosurgery 1986, 2: 74-84.

${ }^{37}$ Ligget PE, Can M, Green RL, Lean JS, Rao NA: Intraocular Inflammatory and Toxic Effects of a nęw Tissue Adhesive for Retinopexy: Mussel Adhesive Protein. Invest Ophthalmol Vis Sci 1987, Suppl 28

${ }^{38}$ Peyman GA, Nasaduke I, Rednam KV: Internal Patching of Posterior Tears using Autologous Ocular Tissues. Exp Ophthalmol (Coimbra) 1984, 10: 12-16.

${ }^{39}$ Leonard F, Kulkarni RK, Brandes G, Nelson J, Cameron JJ: Synthesis and Degradation of Polyalkyl Cyanoacrylates. J Appl Sci 1966, 10: 259-72.

${ }^{40}$ Nesburn AB, Ziniti P: Cell Culture Toxicity of Two Cyanoacrylate Adhesives. Invest Ophthalmol Vis Sci 1969, Suppl 648 